\title{
Solvation Effects Adjacent to the Reaction Site. Differences in Solvation between Alkyl, Alkenyl, or Alkynyl and Aryl Groups in Binary Aqueous Mixtures
}

\author{
T. William Bentley,* Jan-Peter Dau-Schmidt, Gareth Llewellyn, and Herbert Mayr ${ }^{\dagger}$ \\ Department of Chemistry, University College of Swansea, Singleton Park, Swansea SA2 8PP, Wales, U.K., and \\ Institut fur Chemie, Medzinische Universitat zu Lübeck, Ratzeburger Allee 160, W-2400 Lübeck 1, Germany
}

\author{
Received September 16, 1991
}

\begin{abstract}
Rate constants for solvolyses of 4-chloropent-2-ene ( $\alpha, \gamma$-dimethylallyl chloride, 1$)$ and 4-chloro-4-methylpent-2-yne (2) are reported for aqueous binary mixtures with acetonitrile, acetone, dioxane, ethanol, and methanol. Additional kinetic data are reported for solvolyses of 2-chloro-2-methylpentane (3) in acetone/water and ethanol/water and for tert-butyl chloride in acetonitrile/water. The response to changes in solvent ionizing power (Grunwald-Winstein $m$ value) is almost identical for solvolyses of 1,2 , and p-methoxybenzyl chloride (4). Comparison of data for solvolyses of 1 and 2 with published rate constants for solvolyses of tert-butyl chloride and of 4 show deviations from the ethanol/water correlation line (dispersion) in the order: aryl $\gg$ propargyl $>$ allyl $>$ alkyl; these trends are attributed to differences in solvation of the part of the alkyl group (R) adjacent to the reaction site. Allowance for specific solvation of $\mathbf{R}$ groups guides the choice of "similarity models" to improve the precision and reliability of predictions using the Grunwald-Winstein and related equations for aqueous binary mixtures; prediction of solvent effects on solvolytic reactivity can be achieved using $Y_{\text {sim }}$ values.
\end{abstract}

The Grunwald-Winstein equation (1) ${ }^{1 \mathrm{a}}$ relates logarithms of solvolysis rate constants $(k)$ to the solvent ionizing power $Y$, defined relative to the rate constant for solvolyses of tert-butyl chloride in $80 \% \mathrm{v} / \mathrm{v}$ ethanol/water at $25^{\circ} \mathrm{C}\left(k_{0}\right)$ with $m-1$. For substrates other than tert. butyl chloride, both $m$ and $\log k_{0}$ are adjustable parameters, ${ }^{1}$ so $k_{0}$ has a dual role. For solvolyses of tert-butyl chloride, $k_{0}$ is an experimental rate constant, whereas for other substrates it approximates to the rate constant in $80 \%$ ethanol but it is actually an adjustable parameter. To avoid this duality, there is an alternative, more usual, ${ }^{2}$ procedure in which $k_{0}$ always refers to observed rate constants for solvolyses in $80 \%$ ethanol/water and $m$ and $c$ are then the two adjustable parameters (eq 2).

$$
\begin{aligned}
& \log k=m Y+\log k_{0} \\
& \log \left(k / k_{0}\right)=m Y+c
\end{aligned}
$$

Although eq 1 was originally devised to predict solvolysis rate constants in one solvent from published data in another solvent, ${ }^{1 b}$ it has usually been used to correlate data in various solvents, or to obtain extra data by interpolation for a particular binary aqueous mixture. ${ }^{3}$ Equation 2 is commonly written without the intercept (c), which is not required for typical interpolations, but $c$ is often a "hidden" adjustable parameter in correlations (for critical comments, see ref 4).

Deviations from linear rate-rate correlations, e.g., for solvolyses of carboxylic acid chlorides ${ }^{5}$ and sulfonyl chlorides, ${ }^{6}$ were interpreted as indications of mechanistic changes and these predictions were confirmed independently from trends in product selectivities.

In connection with our interest in the kinetics of $\mathrm{CC}$ bond formation by addition of carbenium ions to $\pi$-nucleophiles, ${ }^{7}$ a good correlation was found ${ }^{7 \mathrm{a}}$ for logarithms of rate constants for reactions of alkyl chlorides (with allyltrimethylsilane) versus their ethanolysis rate constants. Literature rate constants for a much wider range of solvolyses of alkyl chlorides are available in solvents other than pure ethanol (typically acetone/water, dioxane/water, or ethanol/water mixtures). To extend the scope of the correlation, ${ }^{7 a}$ we needed to harness the predictive power

\footnotetext{
'Present address: Institut für Organische Chemie, Technische Hochschule, Petersenstrasse 22, W-6100 Darmstadt, Germany.
}

of eq 1 and/or related equations to calculate data in pure ethanol.

If eq 1 applies (e.g., the plot is linear), a knowledge of $Y$ and $m$ values is sufficient for predictions converting results in ethanol/water to pure ethanol, and the required $m$ values could be based on $m$ values in similar systems. A serious difficulty arises for correlations of solvolysis rates in different binary aqueous mixtures, because there is usually "dispersion" into separate correlation lines for the various binary aqueous mixtures, ${ }^{8}$ e.g., for solvolyses of diphenylmethyl chloride, the rate constant for solvolysis in the acetone/water composition having $Y=-2$ is over 50 times smaller than solvolysis in an ethanol/water mixture of the same $Y$ value. ${ }^{8 \mathrm{a}}$ The predictive power of eqs 1 and 2 is much reduced, because intercepts depend on the particular aqueous binary mixture and on the substrate (e.g., see Table II of ref $8 \mathrm{~b}$ ).

It has been shown recently $y^{9,10}$ that there are differences in solvation between aryl and alkyl groups adjacent to the reaction site in solvolytic reactions, and we now extend this work by examining the effect of alkenyl and alkynyl groups. We also generalize all of these results using a new approach based on "similarity models".

(1) (a) Grunwald, E.; Winstein, S. J. J. Am. Chem. Soc. 1948, 70, 846. (b) Grunwald, E. Current Contents 1984, 43, 18.

(2) (a) Swain, C. G.; Dittmer, D. C.; Kaiser, L. E. J. Am. Chem. Soc. 1955, 77, 3737. (b) Bentley, T. W.; Schleyer, P. v. R. J. Am. Chem. Soc. 1976, 98, 7658. (c) Kevill, D. N.; Ismail, N. H. J. J. Org. Chem. 1991, 56, 3454 .

(3) (a) Streitwieser, A., Jr. Chem. Reu. 1956, 56, 617. (b) Bentley, T. W.; Llewellyn, G. Prog. Phys. Org. Chem. 1990, 17, 121.

(4) Bentley, T. W.; Bowen, C. T.; Morten, D. H.; Schleyer, P. v. R. J. Am. Chem. Soc. $1981,103,5466$

(5) Bentley, T. W.; Koo, I. S. J. Chem. Soc., Perkin Trans. 2 1989, 1385 .

(6) Koo, I. S.; Bentley, T. W.; Kang, D. H.; Lee, I. J. Chem. Soc., Perkin Trans. 2 1991, 175.

(7) (a) Mayr, H. Angew. Chem., Int. Ed., Engl. 1990, 29, 1371. (b) Mayr, H.; Schneider, R.; Schade, C.; Bartl, J.; Bederke, R. J. Am. Chem. Soc. 1990, 112, 4446. (c) Mayr, H.; Schneider, R.; Irrgang, B.; Schade, C. J. Am. Chem. Soc. $1990,112,4454$. (d) Mayr, H.; Schneider, R.; Grabis, U. J. Am. Chem. Soc. 1990, 112, 4460. (e) Hagen, G.; Mayr, H. J. Am. Chem. Soc. 1991, 113, 4954.

(8) (a) Winstein, S.; Fainberg, A. H.; Grunwald, E. J. Am. Chem. Soc. 1957, 79, 4146. (b) Fainberg, A. H.; Winstein, S. J. Am. Chem. Soc. 1957, $79,1597$.

(9) Liu, K.-T.; Sheu, H.-C. J. Org. Chem. 1991, 56, 3021. 1604.

(10) Bentley, T. W.; Koo, I. S.; Norman, S. J. J. Org. Chem. 1991, 56,

(11) Zalewski, R. I.; Krygowski, T. M.; Shorter, J. Similarity Models in Organic Chemistry, Biochemistry and Related Fields; Elsevier: New York, 1991. 
Table I. Rate Constants $(k)$ for Solvolyses of 4-Chloro-4-methylpent-2-yne (2) in Highly Aqueous Mixtures"

\begin{tabular}{ccccc}
\hline solvent & & \multicolumn{1}{c}{$k, \mathrm{~s}^{-1}$} & $\begin{array}{c}\Delta H^{*}, \mathrm{kcal} \\
\mathrm{mol}^{-1}\end{array}$ & $\begin{array}{c}\Delta S^{*}, \mathrm{cal} \\
\mathrm{mol}^{-1} \mathrm{~K}^{-1}\end{array}$ \\
\hline $20 \mathrm{~A}$ & $0.1^{d}$ & $(3.84 \pm 0.20) \times 10^{-2}$ & & \\
& 25.0 & $(6.78 \pm 0.28) \times 10^{-1}$ & 18.1 & 1.4 \\
$40 \mathrm{D}$ & 0.1 & $(2.02 \pm 0.03) \times 10^{-3}$ & & \\
& $25.0^{d}$ & $(3.75 \pm 0.02) \times 10^{-2}$ & 18.4 & -3.3 \\
$20 \mathrm{D}$ & 0.1 & $(3.15 \pm 0.27) \times 10^{-2}$ & & \\
& $25.0^{d}$ & $(5.36 \pm 0.20) \times 10^{-1}$ & 17.9 & 0.1 \\
$20 \mathrm{E}$ & $25.0^{d}$ & $(9.03 \pm 0.23) \times 10^{-1}$ & & \\
$40 \mathrm{M}$ & 0.1 & $(1.15 \pm 0.03) \times 10^{-2}$ & & \\
& $25.0^{d}$ & $(2.16 \pm 0.02) \times 10^{-1}$ & 18.5 & 0.5 \\
$20 \mathrm{M}$ & 0.1 & $(4.90 \pm 0.07) \times 10^{-2}$ & & \\
& $25.0^{d}$ & $1.2 \pm 0.07$ & 20.0 & 9.7
\end{tabular}

- Determined conductimetrically in duplicate except where stated otherwise; errors shown are average deviations. ${ }^{b}$ Solvent compositions are $\% \mathrm{v} / \mathrm{v}$ and solvent codes are acetone $(\mathrm{A})$, acetonitrile (An), dioxane (D), ethanol (E), and methanol (M). ' Calculated from data at other temperatures. ${ }^{d}$ Triplicate measurement of rate constant.

Table II. Rate Constants $(k)$ for Solvolyses of 4-Chloropent-2-ene (1) in Highly Aqueous Mixtures ${ }^{\circ}$

\begin{tabular}{cclcc}
\hline solvent ${ }^{b}$ & temp, ${ }^{\circ} \mathrm{C}$ & \multicolumn{1}{c}{$k, \mathrm{~s}^{-1}$} & $\begin{array}{c}\Delta H^{*}, \mathrm{kcal} \\
\mathrm{mol}^{-1}\end{array}$ & $\begin{array}{c}\Delta S^{*}, \mathrm{cal} \\
\mathrm{mol}^{-1} \mathrm{~K}^{-1}\end{array}$ \\
\hline $20 \mathrm{~A}$ & $0.1^{e}$ & $(2.55 \pm 0.3) \times 10^{-1}$ & & \\
& $25.0^{c}$ & 3.8 & & $(1.4)^{f}$ \\
$40 \mathrm{D}$ & 0.1 & $(2.84 \pm 0.01) \times 10^{-2}$ & & \\
& 25.0 & $(3.94 \pm 0.08) \times 10^{-1}$ & 16.5 & -4.9 \\
$20 \mathrm{D}$ & 0.1 & $(2.54 \pm 0.3) \times 10^{-1}$ & & \\
& $25.0^{c}$ & 3.6 & & $(0.1)^{f}$ \\
$20 \mathrm{E}$ & $-10.0^{d}$ & $(1.16 \pm 0.01) \times 10^{-1}$ & & \\
& 0.6 & $(5.43 \pm 0.12) \times 10^{-1}$ & $(20.3)$ & $(14.6)$ \\
$40 \mathrm{M}$ & $25.0^{c}$ & $(12)$ & & \\
& 0.1 & $1.33 \pm 0.01 \times 10^{-1}$ & & \\
& $25.0^{d}$ & $1.64 \pm 0.03$ & 15.8 & -4.7 \\
$20 \mathrm{M}$ & $25.0^{c}$ & 2.0 & & $(0.5)^{f}$ \\
& $-10.2^{d}$ & $(1.04 \pm 0.07) \times 10^{-1}$ & & \\
& 0.0 & $(4.44 \pm 0.08) \times 10^{-1}$ & 19.7 & 12.2 \\
& $25.0^{c}$ & 10 & &
\end{tabular}

${ }^{a-d}$ As for Table I. 'Quadruplicate measurement of rate constant. 'Calculated by an iterative procedure, based on the assumption that $\Delta S^{*}$ is the same as that for solvolysis of 2 in the same solvent (Table I).

\section{Results}

The fast-response conductimetric method ${ }^{12}$ was required for solvolyses of 4-chloropent-2-ene (1) and 4-chloro-4methylpent-2-yne (2) in highly aqueous media (Tables I and II). Supporting the reliability of these data, the precision of fit to first-order kinetics was good (calculated and observed conductance values agreed within about $0.1 \%$ over at least 3 half-lives); entropies of activation for solvolyses of 2 (Table I) are very similar to those reported previously for solvolyses of tert-butyl chloride in the same solvent. ${ }^{16}$ Because 1 was too reactive for direct mea-

(12) Bentley, T. W.; Kirmse, W.; Llewellyn, G.; Sollenbohmer, F. J Org. Chem. 1990, 55, 1536

(13) (a) Goering, H. L.; Nevitt, T. D.; Silversmith, E. F. J. Am. Chem. Soc. 1955, 77, 5026. (b) Sneen, R. A.; Bradley, W. A. J. Am. Chem. Soc. $1972,94,6975$.

(14) Shiner, V. J., Jr.; Kriz, G. S., Jr. J. Am. Chem. Soc. 1964, 86, 2643.

(15) (a) Shiner, V. J. Jr. J Am. Chem. Soc. 1961, 83, 240. (b) Brown, H. C.; Fletcher, R. S. J. Am. Chem. Soc. 1949, 71, 1845. (c) Shorter, J.; Hinshelwood, C. J. Chem. Soc. 1949, 2412.

(16) (a) Fainberg, A. H.; Winstein, S. J. Am. Chem. Soc. 1956, 78, 2770.

(b) Winstein, S.; Fainberg, A. H. J. Am. Chem. Soc. 1957, 79, 5937.

(17) (a) Bunton, C. A.; Mhala, M. M.; Moffatt, J. R. J. Org. Chem. 1984, 49, 3637. (b) Bunton, C. A.; Mhala, M. M.,; Moffatt, J. R. J. Org. Chem. 1984, 49, 3639. (c) Robertson, R. E.; Sugamori, S. E. Can. J. Chem $1972,50,1353$.
Table III. Rate Constants (k) for Solvolyses of 4-Chloropent-2-ene (1) and 4-Chloro-4-methylpent-2-yne (2) in Binary Aqueous Mixtures at $25{ }^{\circ} \mathrm{C}^{a}$

\begin{tabular}{lll}
\hline & \multicolumn{2}{c}{$k, \mathrm{~s}^{-1}$} \\
\cline { 2 - 3 } solvent ${ }^{b}$ & \multicolumn{1}{c}{1} & \multicolumn{1}{c}{2} \\
\hline ethanol & $(4.57 \pm 0.12) \times 10^{-5 d, e}$ & $(7.56 \pm 0.04) \times 10^{-6 d}$ \\
$90 \mathrm{E}$ & $(7.42 \pm 0.08) \times 10^{-4} f$ & $(1.01 \pm 0.02) \times 10^{-4}$ \\
$80 \mathrm{E}$ & $(4.3 \pm 0.1) \times 10^{-3}$ & $5.42 \times 10^{-4} \mathrm{~g}$ \\
$60 \mathrm{E}$ & $(5.70 \pm 0.07) \times 10^{-2}$ & $(6.33 \pm 0.12) \times 10^{-3}$ \\
$40 \mathrm{E}$ & $(7.5 \pm 0.1) \times 10^{-1}$ & $(8.75 \pm 0.05) \times 10^{-2}$ \\
$20 \mathrm{E}^{h}$ & 12 & $(9.03 \pm 0.23) \times 10^{-1}$ \\
methanol & $(5.8 \pm 0.2) \times 10^{-4}$ & $(8.77 \pm 0.08) \times 10^{-5}$ \\
$80 \mathrm{M}$ & $(1.49 \pm 0.01) \times 10^{-2}$ & $(2.19 \pm 0.02) \times 10^{-3}$ \\
$60 \mathrm{M}$ & $(1.92 \pm 0.03) \times 10^{-1}$ & $(2.47 \pm 0.05) \times 10^{-2}$ \\
$40 \mathrm{M}^{h}$ & 1.8 & $(2.16 \pm 0.02) \times 10^{-1}$ \\
$20 \mathrm{M}^{h}$ & 10 & $1.2 \pm 0.07$ \\
$90 \mathrm{~A}$ & $(3.5 \pm 0.1) \times 10^{-5 i}$ & \\
$80 \mathrm{~A}$ & $(5.64 \pm 0.05) \times 10^{-4}$ & $(6.02 \pm 0.23) \times 10^{-5} j$ \\
$60 \mathrm{~A}$ & $(2.24 \pm 0.02) \times 10^{-2}$ & $(2.27 \pm 0.08) \times 10^{-3}$ \\
$40 \mathrm{~A}$ & $(4.30 \pm 0.03) \times 10^{-1}$ & $(4.60 \pm 0.02) \times 10^{-2}$ \\
$20 \mathrm{~A}^{h}$ & 3.8 & $(6.78 \pm 0.28) \times 10^{-1}$ \\
$90 \mathrm{An}$ & $(2.16 \pm 0.05) \times 10^{-4}$ & \\
$80 \mathrm{An}$ & $(2.45 \pm 0.04) \times 10^{-3}$ & $(3.50 \pm 0.13) \times 10^{-4}$ \\
$60 \mathrm{An}$ & $(4.03 \pm 0.01) \times 10^{-2}$ & $(4.69 \pm 0.12) \times 10^{-3}$ \\
$40 \mathrm{An}$ & $(4.20 \pm 0.26) \times 10^{-1}$ & $(4.55 \pm 0.05) \times 10^{-2}$ \\
$90 \mathrm{D}$ & $(3.21 \pm 0.05) \times 10^{-6} d, k$ & \\
$80 \mathrm{D}$ & $(4.43 \pm 0.03) \times 10^{-4 i}$ & $(3.47 \pm 0.3) \times 10^{-5 i}$ \\
$60 \mathrm{D}$ & $(1.45 \pm 0.10) \times 10^{-2}$ & $(1.50 \pm 0.01) \times 10^{-3} i$ \\
$40 \mathrm{D}^{h}$ & $(3.94 \pm 0.08) \times 10^{-1}$ & $(3.75 \pm 0.02) \times 10^{-2}$ \\
$20 \mathrm{D}^{h}$ & 3.6 & $(5.36 \pm 0.2) \times 10^{-1}$ \\
& &
\end{tabular}

${ }^{a, b}$ As for Table I. ' Calculated from data at higher temperatures. ${ }^{d}$ Lutidine added. ${ }^{e}$ Other kinetic data: $k=7.59 \times 10^{-5} \mathrm{~s}^{-1}$ at $30^{\circ} \mathrm{C}$ (ref 13a) and $k_{\mathrm{t}}=1.33 \times 10^{-4}$ at $36^{\circ} \mathrm{C}$ (ref $13 \mathrm{~b}$ )-also $k_{\alpha} / k_{\mathrm{t}}=2.32$ (ref $13 \mathrm{~b}$ ). 'Other kinetic data: $k_{\mathrm{t}}=8.40 \times 10^{-4} \mathrm{~s}^{-1}$ at $27^{\circ} \mathrm{C}$ and $k_{\alpha} / k_{\mathrm{t}}=1.23$ (ref $13 \mathrm{~b}$ ). ${ }^{8}$ Reference 14. ${ }^{h}$ Data from Tables I and II. ${ }^{i}$ Lutidine was added to one of the two kinetic runs. ${ }^{i}$ Lit. $5.87 \times$ $10^{-5}$ (ref 14$) .{ }^{k}$ Duplicate runs without lutidine gave $k=(3.41 \pm$ $0.04) \times 10^{-5}$

Table IV. Rate Constants ( $k$ ) for Solvolyses of 2-Chloro-2-methylpentane (3) in $80 \% \mathrm{v} / \mathrm{v}$ Acetone/Water and Ethanol/Water

\begin{tabular}{ccccc}
\hline solvent & temp, ${ }^{\circ} \mathrm{C}$ & \multicolumn{1}{c}{$k, \mathrm{~s}^{-1}$} & $\begin{array}{c}\Delta H^{*}, \mathrm{kcal} \\
\mathrm{mol}^{-1}\end{array}$ & $\begin{array}{c}\Delta S^{*}, \mathrm{cal} \\
\mathrm{mol}^{-1} \mathrm{~K}^{-1}\end{array}$ \\
\hline $80 \mathrm{~A}$ & $50.0^{b}$ & $(5.12 \pm 0.03) \times 10^{-5}$ & & \\
$80 \mathrm{~A}$ & $30.0^{b}$ & $(5.35 \pm 0.25) \times 10^{-6}$ & 21.4 & -12.2 \\
$80 \mathrm{~A}$ & $25.0^{\mathrm{c}}$ & $2.9 \times 10^{-6}$ & & \\
$80 \mathrm{E}$ & $25.0^{d, \mathrm{e}}$ & $\begin{array}{l}1.53 \times 10^{-5} \\
(2.24 \pm 0.05) \times 10^{-3}\end{array}$ & $(23.5)$ & $(-1.6)$ \\
$40 \mathrm{E}$ & 25.0 & $(2.0)$ &
\end{tabular}

a As for Table I. ${ }^{b}$ Lutidine buffer was added to one of the two kinetic runs. 'Calculated from data at higher temperatures. ${ }^{d}$ Reference $15 \mathrm{a}$. 'Other rate constants: $k=1.44 \times 10^{-5} \mathrm{~s}^{-1}$ at 25 ${ }^{\circ} \mathrm{C}$ (ref $15 \mathrm{~b}$ ) and $k=5.74 \times 10^{-5} \mathrm{~s}^{-1}$ at $35^{\circ} \mathrm{C}$ (ref $15 \mathrm{c}$ )

surement at $25^{\circ} \mathrm{C}$ in the highly aqueous media, activation entropies were assumed in some extrapolations from 0 to $25^{\circ} \mathrm{C}$ (Table II). Solvolyses of 1 in $20 \%$ ethanol/water and methanol/water were particularly difficult to study, and it may be that dissolution and solvolysis occur at similar rates; despite the extrapolated rate constants of 12 and 10 , respectively (Table II), it seems unlikely that the solvolysis of 1 in $20 \%$ ethanol/water is faster than that in $20 \%$ methanol/water.

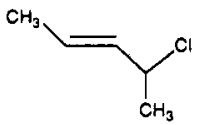

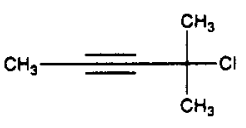

2
The precision of some of the slower runs was improved when lutidine was added, and agreement with the limited published data is satisfactory. All of the available kinetic data are summarized in Table III. 
Table V. Solvolyses of tert-Butyl Chloride in Acetonitrile/Water ( $\%$ v/v An) at $25{ }^{\circ} \mathrm{C}$ and Grunwald-Winstein $\boldsymbol{Y}$ Values (eq 1$)^{a}$

\begin{tabular}{clr}
\hline composition & \multicolumn{1}{c}{$k, \mathrm{~s}^{-1}$} & \multicolumn{1}{c}{$Y$} \\
\hline $90 \mathrm{An}^{c, d}$ & $5.5 \times 10^{-7}$ & -1.23 \\
$80 \mathrm{An}^{e}$ & $(6.7 \pm 0.02) \times 10^{-6}$ & -0.14 \\
$70 \mathrm{An}$ & $(3.12 \pm 0.05) \times 10^{-5}$ & 0.53 \\
$60 \mathrm{An}^{f}$ & $9.2 \times 10^{-5}$ & 1.00 \\
$50 \mathrm{An}^{f}$ & $2.9 \times 10^{-4}$ & 1.50 \\
$40 \mathrm{An}^{f}$ & $8.7 \times 10^{-4}$ & 1.97 \\
$30 \mathrm{An}^{f}$ & $2.5 \times 10^{-3}$ & 2.43 \\
$20 \mathrm{An}^{f}$ & $6.7 \times 10^{-3}$ & 2.86
\end{tabular}

${ }^{a}$ As for Table I. ${ }^{b}$ The $k_{0}$ value in $80 \%$ ethanol/water is $9.26 \times$ $10^{-6}$ (ref 16 ). 'Calculated from rate data at higher temperatures. ${ }^{d}$ At $75.2^{\circ} \mathrm{C}, k=(1.58 \pm 0.05) \times 10^{-4}$ and at $50.1, k=(1.16 \pm 0.04)$ $\times 10^{-5}, \Delta H^{*}=22.6 \mathrm{kcal} / \mathrm{mol}, \Delta S^{*}=-11.3$ (data from $\mathrm{S}$. Norman). ${ }^{e}$ One conductimetric and duplicate titrimetric runs (S. Norman). Calculated from rate data in $\% \mathrm{w} / \mathrm{w}$ water/acetonitrile (refs $17 \mathrm{a}$ and 17c), giving $\log k=0.0494$ (wt \%) $-6.3026(r=0.9995)$ from 90 to $40 \% \mathrm{w} / \mathrm{w}$ water/acetonitrile.

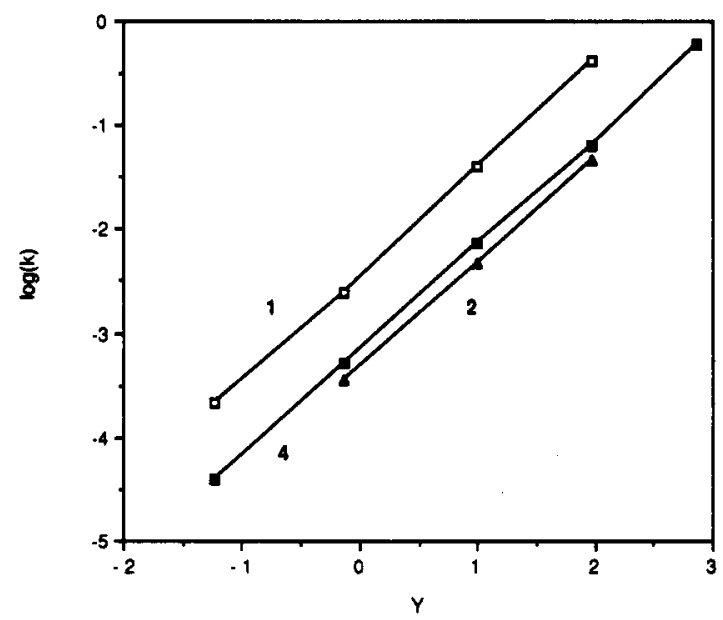

Figure 1. Correlation of logarithms of rate constants for solvolyses of 4-chloropent-2-ene (1; slope 1.03), 4-chloro-4-methylpent-2-yne (2; slope 1.00), and $p$-methoxybenzyl chloride (4; slope 1.01) in acetonitrile/water mixtures with $Y$ values (Table V); $r=1.000$ in all three cases (additional kinetic data from ref 10 ).

Data for solvolyses of 2-chloro-2-methylpentane (3) in Table IV and for solvolyses of tert-butyl chloride in acetonitrile/water (Table V) were obtained by standard methods. ${ }^{18}$ In addition to typical cosolvents (acetone, dioxane, ethanol, and methanol), we have studied acetonitrile/water mixtures because it is a good cosolvent for any studies requiring UV detection ${ }^{17 \mathrm{a}}$ and its use for solvolyses is increasing. ${ }^{19}$

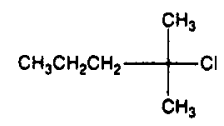

3

\section{Discussion}

There are excellent linear correlations of unit slope between logarithms of solvolysis rates for $1(m=1.03), 2$ $(m=1.00)$, and $4(m=1.01)$ with $Y$ values (Figure 1$)$ in acetonitrile/water mixtures, and the almost identical $m$ values (eq 1) indicate that $m$ values for structurally-related substrates can also be assumed to be 1.0. Acetonitrile/ water appears to be one of the less complicated aqueous

(18) Bentley, T. W.; Carter, G. E. J. Am. Chem. Soc. 1982, 104, 5741

(19) (a) Richard, J. P.; Jencks, W. P. J. Am. Chem. Soc. 1984, 106, 1383. (b) Thibblin, A.; J. Chem. Soc., Perkin Trans. 2 1987, 1629.

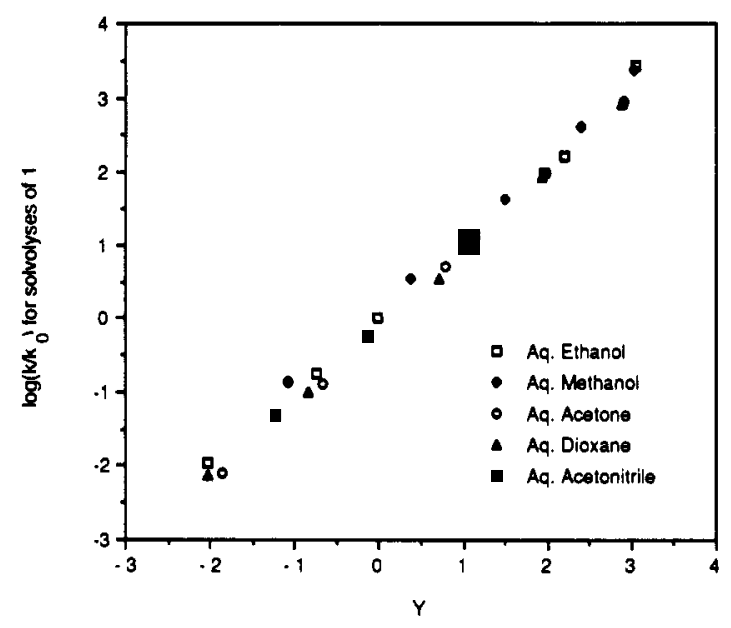

Figure 2. Correlation of rate constants $\left(\log k / k_{0}\right)$ for solvolyses of 4-chloropent-2-ene (1) in aqueous binary water mixtures with $Y$ values; kinetic data from Table III and $Y$ values from ref 16 .

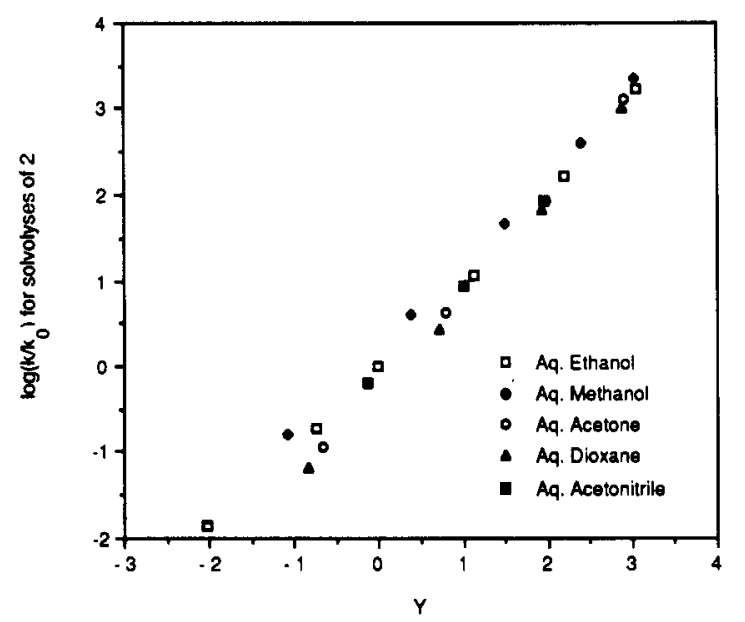

Figure 3. Correlation of rate constants $\left(\log k / k_{0}\right)$ for solvolyses of 4-choro-4-methylpent-2-yne (2) in aqueous binary water mixtures with $Y$ values; kinetic data from Table III and $Y$ values from ref 16.

binary mixtures, because acetonitrile competes successfully with water-water interactions and destroys the lattice structure. ${ }^{17 \mathrm{c}, 20}$ These results may imply that acetonitrile/water is the best solvent in which to determine $m$ values, although ethanol/water mixtures (the usual choice) give very similar results as shown below.

Recent work on solvolyses of $p$-methoxybenzyl chloride (4) ${ }^{10}$ and 2-aryl-2-adamantyl chlorides $5^{9}$ in aqueous acetone, ethanol, and methanol shows marked dispersion effects in correlations with $Y$ or $Y_{\mathrm{Cl}}$. As these data have a common point at pure water, dispersion also leads to variations in the slope ( $m$, eq 1 and 2$)$ and/or to curved plots for the various aqueous binary mixtures. Typical dispersion effects are shown in Figures 2-4 for solvolyses of 1,2 , and 4 . The convergence data point for pure water was too difficult to measure directly using presently available techniques. Comparison of Figures 2-4 shows that dispersion varies in the order $4>2>1$, consistent with proposals ${ }^{9,10}$ that this effect is due to specific solvation of the $\pi$-system. Assessing dispersion relative to acetonitrile/water for solvents of the same $Y$ value, mixtures of ethanol/water and methanol/water (to a larger extent)

(20) (a) Armitage, D. A.; Blandamer, M. J.; Foster, M. J.; Hidden, N. J.; Morcom, K. W.; Symons, M. C. R.; Wootten, M. J. Trans Faraday Soc. 1968, 64, 1193. (b) Blandamer, M. J. Adv. Phys. Org. Chem. 1977, 14, 203 (c) Miyaji, K.; Morinaga, K. Bull. Chem. Soc. Jpn. 1986, 59, 1695. 


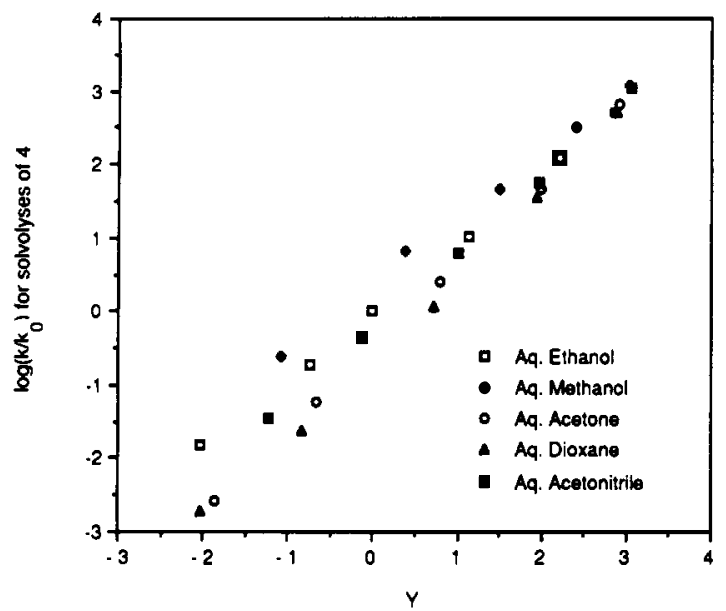

Figure 4. Correlation of rate constants $\left(\log k / k_{0}\right)$ for solvolyses of $p$-methoxybenzyl chloride (4) in aqueous binary water mixtures with $Y$ values; kinetic data from ref 10 and $Y$ values from ref 16 .

react faster with substrates having a $\pi$-system adjacent to the reaction site, whereas acetone/water and dioxane/ water mixtures react more slowly.

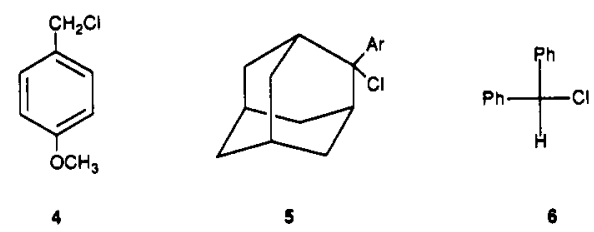

In the above work, dispersion effects have been analyzed by plotting the results against $Y$ (Figures 1-4), but a limitation of $Y$ values is that they include a contribution from solvent nucleophilicity. ${ }^{17 b, 18,21} Y_{\mathrm{Cl}}$ values, based on solvolyses of 1-adamantyl chloride, are free of nucleophilic solvation effects $^{3 b}$ and would have given similar results because the binary mixtures investigated have very similar nucleophilicities; ${ }^{22}$ they were not employed because data were not available for the whole range of binary aqueous mixtures and some values have been estimated in correlations with $Y^{18}$

It was also suggested ${ }^{9}$ that dispersion was associated with delocalization of positive charge, e.g., for solvolyses of 2-aryl-2-adamantyl substrates $\mathbf{5}, m$ values are lowered from the 1.0 expected $^{3 \mathrm{~b}}$ for adamantyl systems to $0.67-0.90 .^{9}$ However, the relationship between variations of $m$ and dispersion is not clear. Similar delocalization of charge within the allyl group in 1 and the $p$-methoxyphenyl group in 4 would have also been expected to reduce $m$ values, but this is not observed (Figure 1).

Assuming that the "true" $m$ value for solvolyses of 1,2 , 4 , and 5 is the same as that for tert-butyl chloride, dispersion can be compared by plotting $\left[\log \left(k / k_{0}\right)-Y\right]$ vs $Y$ (see Figure 5). In the absence of dispersion, a horizontal correlation line would be observed at 0.0 on the $y$-axis (the hatched line in Figure 5) for acetone/water mixtures. In general, the order of deviation from this expectation is 6 $>4>5>2>1$.

Despite the expected charge delocalization (conjugative effect), dispersion caused by an allyl group is small. The methyl group attached to the triple bond in 2 accelerates the solvolysis 2000 -fold (compared to $\mathrm{H}$ ) in $80 \%$ etha-

(21) Kevill, D. N.; Anderson, S. W. J. Am. Chem. Soc. 1986, 108, 1579 (22) (a) Schadt, F. L.; Bentley, T. W.; Schleyer, P. v. R. J. Am. Chem. Soc. 1976, 98, 7667. (b) Kevill, D. N.; Lin, G. M. L. J. Am. Chem. Soc. 1979, 101, 3916. (c) Kevill, D. N.; Anderson, S. W. J. Org. Chem. 1991, $56,1845$.

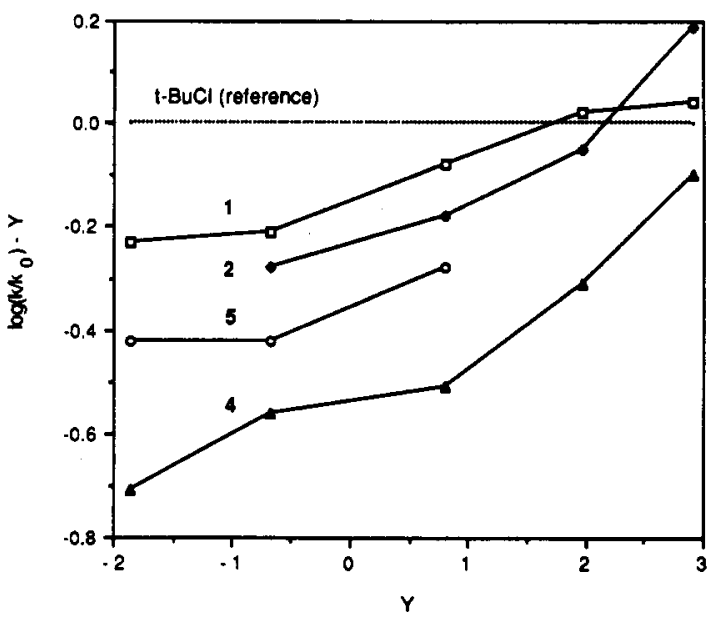

Figure 5. Correlation of $\left[\log \left(k / k_{0}\right)-Y\right]$ for solvolyses of 4chloropent-2-ene (1), 4-choro-4-methylpent-2-yne (2), $p$-methoxybenzyl chloride (4), and 2-(3'-chlorophenyl)-2-adamantyl chloride (5) in acetone/water mixtures with $Y$ values (ref 16 ); additional kinetic data from refs 9 and 10 .

nol/water at $25^{\circ} \mathrm{C}, 23$ presumably by a combination of conjugative and hyperconjugative effects. Hence, dispersion appears to depend on the number of adjacent $\pi$-electrons, but the phenomenon cannot readily be associated with a specific type of charge stabilization. In related work, dispersion between correlations for ethanol/ water and acetic acid/formic acid mixtures has been used as a test to try to distinguish between neighboring group assistance by $\sigma$-conjugation and by bridging. ${ }^{24}$ Also, pairwise interactions between functional groups in the substrate and the solvent (Savage-Wood treatment) are being evaluated for highly aqueous binary mixtures. ${ }^{25}$

Whereas eq 2, based on tert-butyl chloride $(m=1, c=$ $0)$ correctly predicts the solvolysis rate constant for 2 chloro-2-methylpentane (3, Table IV) in $80 \%$ acetone/ water [observed $\log \left(k / k_{0}\right)$ value, -0.72 ; calculated $\left.-0.67^{16}\right)$, observed values for solvolyses of 1 and 2 are significantly lower $(-0.88$ and -0.95 , respectively). Hence, there is a significant difference in solvation effect for a saturated propyl group in comparison with the unsaturated groups. Since 3 has the same number of carbon atoms as 2 , dispersion cannot be explained by the increase in the number of carbon atoms around the reaction site.

The primary aim of this work, prediction of solvolysis rate constants in one solvent from data in another solvent, can now be considered. By making suitable choices of slope $(m)$ and intercept $(c)$, the results could be interpreted in terms of $Y$ values (eq 2), but there would be a loss in precision because some of the plots are slightly curved (Figures 2-4). To accommodate dispersion effects and any small variations in $m$ values, we therefore suggest setting $m=1$ and employing different $Y$ scales for different classes of compounds. Suggested choices of these "similarity models" are 1 for allylic compounds, 2 for propargylic compounds, 4 or 5 for benzylic compounds,, 10 and diphenylmethyl chloride (6) for benzhydryl derivatives. ${ }^{26}$

Equation 3 may be employed to generalize and to implement this approach. In eq $3, k$ and $k_{0}$ have the same

$$
\log \left(k / k_{0}\right)=Y_{\text {sim }}
$$

(23) Burawoy, A. Spinner, E J Chem Soc 1954, 3752

(24) Roberts, D. D. J. Org. Chem. 1984, 49, 2521.

(25) Blokzijl, W.; Jager, J.; Engberts, J. B. F. N.; Blandamer, M. J. J. Am. Chem. Soc. 1986, 108, 6411.

(26) Dvorko, G. F.; Ponomareva, E. A.; Kulik, N. I. Russ. Chem. Rev. (Engl. Transl.) 1984, 53, 547. 
Table VI. $\boldsymbol{Y}_{\text {nim }}$ Values (eq 2) for Solvolyses of Similarity Models in Aqueous Mixtures at $25^{\circ} \mathrm{C}$

\begin{tabular}{|c|c|c|c|c|c|c|c|}
\hline \multirow[b]{2}{*}{ solvent ${ }^{a}$} & \multicolumn{7}{|c|}{ models } \\
\hline & $\begin{array}{c}1-\mathrm{AdCl} \\
Y\left({ }_{\mathrm{Cl}}\right)^{b}\end{array}$ & $\begin{array}{c}t \cdot \mathrm{BuCl} \\
(Y)^{c}\end{array}$ & $\begin{array}{c}\text { allyl } \\
Y_{\text {sim }}(1)^{d}\end{array}$ & $\begin{array}{c}\text { propargyl } \\
Y_{\text {sim }}(2)^{d}\end{array}$ & $\begin{array}{l}\text { benzyl } \\
Y_{\text {sim }}(4)^{e}\end{array}$ & $\begin{array}{c}Y_{\mathrm{BnCl}} \\
Y_{\mathrm{sim}}(5)^{\prime}\end{array}$ & $\begin{array}{c}\mathrm{Ph}_{2} \mathrm{CHCl} \\
Y_{\text {tim }}(6)^{8}\end{array}$ \\
\hline ethanol & $(-2.5)^{H}$ & -2.03 & -1.97 & -1.86 & -1.83 & -1.61 & -1.50 \\
\hline $90 \mathrm{E}$ & $(-0.9)^{h}$ & -0.75 & -0.76 & -0.73 & -0.72 & -0.645 & -0.55 \\
\hline $80 \mathrm{E}$ & 0.00 & 0.00 & 0.00 & 0.00 & 0.00 & 0.00 & 0.00 \\
\hline $60 \mathrm{E}$ & 1.38 & 1.12 & 1.12 & 1.07 & 1.01 & 1.07 & $1.01^{i j}$ \\
\hline $40 \mathrm{E}$ & 2.75 & 2.20 & 2.24 & 2.21 & 2.08 & & $2.12^{i, h}$ \\
\hline $20 \mathrm{E}$ & 4.09 & 3.05 & 3.44 & 3.22 & 3.04 & & \\
\hline methanol & $(-1.2)^{h}$ & -1.09 & -0.87 & -0.79 & -0.60 & -0.25 & -0.31 \\
\hline $80 \mathrm{M}$ & $(0.67)^{h}$ & 0.38 & 0.54 & 0.61 & 0.81 & 1.12 & \\
\hline $60 \mathrm{M}$ & 2.07 & 1.49 & 1.65 & 1.66 & 1.66 & & $1.97^{k}$ \\
\hline $40 \mathrm{M}$ & 3.25 & 2.39 & 2.63 & 2.60 & 2.52 & & \\
\hline \multirow{2}{*}{\multicolumn{8}{|c|}{ acetone }} \\
\hline & & & & & & & \\
\hline $90 \mathrm{~A}$ & & -1.86 & -2.09 & & -2.57 & -2.28 & -2.57 \\
\hline $80 \mathrm{~A}$ & $(-0.8)^{h}$ & -0.67 & -0.88 & -0.95 & -1.23 & -1.09 & -1.37 \\
\hline $60 \mathrm{~A}$ & $(1.00)^{h}$ & 0.80 & 0.72 & 0.62 & 0.39 & 0.52 & $0.27^{k}$ \\
\hline $40 \mathrm{~A}$ & 2.46 & 1.98 & 2.00 & 1.93 & 1.67 & & \\
\hline \multicolumn{8}{|l|}{$\begin{array}{l}20 \mathrm{~A} \\
\text { acetonitrile }\end{array}$} \\
\hline acetonitrile & & $-1.23^{l}$ & -1.30 & & -145 & & \\
\hline $80 \mathrm{An}$ & & $-0.14^{l}$ & -0.24 & -0.19 & -0.35 & & \\
\hline $60 \mathrm{An}$ & & $1.00^{l}$ & 0.97 & 0.94 & 0.81 & & \\
\hline $40 \mathrm{An}$ & & $1.97^{l}$ & 1.99 & 1.92 & 1.74 & & \\
\hline $20 \mathrm{An}$ & $3.75^{m}$ & $2.86^{l}$ & & & 2.72 & & \\
\hline \multicolumn{8}{|l|}{ dioxane } \\
\hline 90D & & -2.03 & -2.13 & & -2.71 & & \\
\hline 80D & & -0.83 & -0.99 & -1.19 & -1.62 & & \\
\hline 60D & & 0.715 & 0.53 & 0.44 & 0.07 & & \\
\hline 40D & & 1.945 & 1.96 & 1.84 & 1.55 & & \\
\hline $20 \mathrm{D}$ & $3.71^{m}$ & 2.88 & 2.92 & 3.00 & 2.72 & & \\
\hline
\end{tabular}

${ }^{a}$ Solvent codes as in Table I. ${ }^{b}$ Reference 18. ${ }^{\mathrm{c}}$ Reference 16. ${ }^{d}$ Data from Table III. ${ }^{e}$ Reference $10 .{ }^{f}$ Reference $9 .{ }^{8}$ Reference 8. ${ }^{h}$ Extrapolated from a plot vs $Y$. ${ }^{i}$ This work. ${ }^{j}$ Reference $17 \mathrm{~b}$ reports 1.56 . ${ }^{k}$ Reference $17 \mathrm{~b}$. ${ }^{l}$ Data from Table V. ${ }^{m}$ Reference 6.

meaning as for eq 2. Data for similarity models, $1,2,4$, 5 , 6, tert-butyl chloride ( $Y$ values), and 1-adamantyl chloride $\left(Y_{\mathrm{Cl}}\right)$ are given in Table VI, which shows the consistent trends in these $Y_{\text {sim }}$ values. To obtain a rate constant in solvent $A$ from a literature rate constant in solvent $B$, one must first choose an appropriate similarity model and then the difference in $Y_{\text {sim }}$ values corrects for the change in solvent (eq 4).

$$
\log k(\mathrm{~A})=\log k(\mathrm{~B})+\left[Y_{\text {sim }}(\mathrm{A})-Y_{\text {sim }}(\mathrm{B})\right]
$$

The underlying principles, suggested from this work, may be considered in the choice of similarity models, e.g., (i) if extensive data for 2 were not available, an appropriate similarity model would be the secondary allylic substrate (1), not tert-butyl chloride, and (ii) a suitable similarity model for solvolyses of 3 is expected to be tert-butyl chloride, not the structurally similar propargyl system 2 . Ambiguities still remain, e.g., for solvolyses involving neighboring group participation by $\sigma$ - and $\pi$-bonds and for the numerous combinations of unsaturated functional groups in primary, secondary and tertiary alkyl chlorides, but our model based on solvation of the $\pi$-systems provides useful predictive insights. Although most data are available for solvolyses of chlorides, the above approach is expected to be applicable also to other leaving groups because leaving group rate ratios are known in many solvents.

Application of the Grunwald-Winstein equations ( 1 and 2) may be considered to be implicit in the above procedure, because an alternative approach is to use the data for an "appropriate" model compound to estimate the slope $(m)$ and intercept (c) and then to apply eq 2 explicitly. More complex mathematical functions of $Y$ (e.g., the quadratic equation $5^{8 b}$ ) could be used to accommodate any curvature.

$$
\log k=a+b Y+c Y^{2}
$$

Similarity models are then implicit in the choice of "appropriate" experimental data on which to base the estimates of $m$ and $c$ (eq 2) or the parameters required for the more complex mathematical functions such as eq 5 . Whichever equation is employed $(1,2,3,5$, or even more complex functions of $Y$ ), these different mathematical procedures should lead to virtually the same predicted result. The reliability of all of these predictions ultimately depends on the same chemically-based assumption-an appropriate choice of similarity model. Hence, although eq 1-3 and 5 are significantly different operationally, they do not differ fundamentally.

We prefer eq 3 and associated $Y_{\text {sim }}$ values (Table VI) because the procedure is straightforward in terms of both concept and implementation. A disadvantage is the proliferation of $Y$ scales, which has already occurred for other parameters employed in physical organic chemistry; however, there are two important differences: (i) there is less ambiguity about which parameters to choose; (ii) there is no claim or implication that $Y_{\text {sim }}$ values have direct fundamental significance.

As the number of $Y$ scales has increased, ${ }^{3,9}$ the subscripted codes have become increasingly esoteric, and for clarity in previous work $\mathrm{k}^{5,6,10,27}$ we have usually shown the name of the model compound on the label for the $x$-axis of plots (except when the original $Y$ values were plotted). The $Y_{\text {sim }}$ equation (3) highlights both the general approach and the requirement to specify a model compound (other than tert-butyl chloride), and labeling of axes could be done as follows: $Y_{\text {sim }}$ (name of model compound); the temperature could also be specified if it differed from 25 ${ }^{\circ} \mathrm{C}$.

(27) (a) Bentley, T. W.; Harris, H. C.; Koo, I. S. J. Chem. Soc., Perkin Trans. 2 1988, 783. (b) Bentley, T. W.; Harris, H. C. J. Chem. Soc., Perkin Trans. 2 1986, 619. 


\section{Conclusions}

Predictions of solvent effects on solvolytic reactivity can be achieved using eq 3 and $Y_{\text {sim }}$ values for appropriate similarity models (Table VI) to account for solvation effects adjacent to the reaction site. Results fit a consistent pattern (for alkyl, alkenyl, alkynyl, and aryl groups in various aqueous binary mixtures), and larger effects are observed when the number of $\pi$-electrons is greater.

Acetonitrile offers useful advantages over organic cosolvents such as acetone and dioxane, previously used extensively in studies of the rates and products of solvolytic reactions in aqueous mixtures.

\section{Experimental Section}

Chemicals. 4-Chloropent-2-ene (1), ${ }^{28}$ 4-chloro-4-methylpent-2-yne (2), ${ }^{29}$ and 2-chloro-2-methylpentane (3) ${ }^{15 \mathrm{~b}}$ were pre-

(28) Mayr, H.; Klein, H.; Kolberg, G. Chem. Ber. 1984, 117, 2555. pared by standard methods and were shown to be pure by ${ }^{1} \mathrm{H}$ NMR. Acetone and methanol (Fisons dried-distilled grade) and acetonitrile (Fisons HPLC grade) were used without further purification. Dioxane $e^{30}$ and ethanol were dried by standard methods. ${ }^{18}$

Kinetics. Conductimetric procedures were as described previously..$^{10,18}$

Acknowledgment. This paper is dedicated to Professor H. C. Brown on the occasion of his 80th birthday. The work was initiated with the aid of a British Council travel grant, and we are grateful to K. T. Liu for helpful comments.

Registry No. 1, 1458-99-7; 2, 999-79-1; 3, 4325-48-8; tert-buty] chloride, 507-20-0; acetonitrile, 75-05-8; water, 7732-18-5.

(29) Mayr, H.; Halberstadt-Kausch, I. K. Chem. Ber. 1982, 115, 3479.

(30) Furniss, B. S.; Hannaford, A. J.; Smith, P. W. G.; Tatchell, A. R. Vogel's Textbook of Practical Organic Chemistry, 5th ed.; Longman (U.K.): $1989 ;$ p 407.

\title{
N-Methylated 2,3'-Bipyridinium Ion. First Synthesis of the More Sterically Hindered Isomer
}

\author{
John A. Zoltewicz,*, Linda B. Bloom, ${ }^{\dagger}$ and William R. Kem \\ Departments of Chemistry and Pharmacology and Therapeutics, University of Florida, \\ Gainesville, Florida 32611-2046
}

Received December 12, 1990 (Revised Manuscript Received March 29, 1991)

\begin{abstract}
1-Methyl-2,3'-bipyridinium salts can be prepared by deprotection of diquaternized precursors. Protecting groups are eliminated from the 1'-position under basic conditions; they include either $p$-nitrostyrene or 1 methyl-2-vinylpyridinium ion. In DMSO- $d_{6}-\mathrm{CD}_{3} \mathrm{OD}$ a nucleophile adds to $1,1^{\prime}$-dimethyl-2,3'-bipyridinium ion to generate a $\sigma$ complex having a nucleophile bonded to the $6^{\prime}$-position.
\end{abstract}

Quaternization of the less reactive nitrogen atom of $2,3^{\prime}$-bipyridine (BIPY) is a challenge. BIPY readily undergoes quaternization with alkylating agents at the sterically less hindered nitrogen atom of the 3-pyridyl ring to give products such as $1 .^{1}$ A second alkyl group may be added to the remaining free nitrogen atom to provide a dication such as 2. Strenuous conditions are required ${ }^{1}$ to $\mathrm{N}$-alkylate 1 because there is both electronic deactivation and steric hindrance of the free nitrogen atom situated ortho to the adjacent cationic ring. Monoquaternized BIPY having an alkyl group bonded to the less reactive, more hindered nitrogen atom of the 2-pyridyl ring has been unknown.

We now report a convenient synthesis of the heretofore unknown 3 containing only an $N$-methyl group at the sterically hindered 2-pyridyl ring and free of other substituents. Our approach is likely to be useful for the preparation of other compounds having two or more nucleophilic nitrogen atoms, one of which normally does not alkylate owing to deactivation for steric and/or electronic reasons as well as for the synthesis of other derivatives of 3 having different $N$-alkyl groups.

An alternate synthetic pathway has been available for derivatives of 3 having substituents bonded to the 4- and 6-positions of the quaternized ring. They have been prepared by a reaction between a primary amine and the corresponding pyrylium ion precursors in which the charged annular nitrogen atom has been replaced by a

\footnotetext{
${ }^{\dagger}$ Department of Chemistry

'Department of Pharmacology and Therapeutics.
}<smiles></smiles><smiles>[PH3+][n+]1ccccc1-c1cccc[n+]1[PH3+]</smiles>

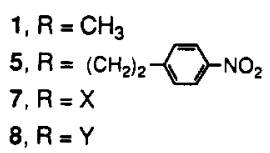<smiles>[2H]P=[PH2]</smiles>
$6, \mathrm{R}_{1}=\left(\mathrm{CH}_{2}\right)_{2}-\mathrm{NO}_{2}$ $\mathrm{R}_{2}=\mathrm{CH}_{3}$ 9. $R_{1}=Y ; R_{2}=\mathrm{CH}_{3}$<smiles>[X]CCc1ccccn1</smiles><smiles>[Y]CCc1cccc[n+]1C</smiles><smiles>C[N+]1(C)C=CC=CC1c1cccnc1</smiles>
3<smiles>C[N+]1(C)CCCC1c1cccnc1</smiles>
4<smiles>[2H]C1([2H])C=CC(c2cccc[n+]2C)=CN1C</smiles>

10

positively charged oxygen atom. ${ }^{2}$ The pyrylium ions themselves require several steps to prepare, ${ }^{3}$ but once the 